\title{
Fault Analysis of Wall Bushing Dielectric Loss and Capacitance of 66kV Exceed the Standard
}

\author{
Zhiqiang Zhang ${ }^{1}$, Yi Zhu ${ }^{1}$, Xin Wei ${ }^{1}$, Yongjie Tong ${ }^{1}$, Fei Han ${ }^{1}$, \\ Xin $\mathrm{Jin}^{2}$, Yongfei Yi ${ }^{2}$, Yuanda Zhu ${ }^{2}$, Su Zhang ${ }^{2}$ \\ 1 Jinzhou Power Supply Company, Liaoning Electric Power Company Limited, State Grid, China \\ ${ }^{2}$ Technical Training Center, Liaoning Electric Power Company Limited, State Grid, China
}

Keywords: Wall Bushing; Insertion Loss; Capacitance; Fault Analysis

\begin{abstract}
Bushing dielectric loss factor measurement test is a very high sensitivity. Through the analysis of the measurement data, it can be judged whether the insulation of the equipment is the whole damp, the deterioration of the insulation, and the local defects of the small capacitor. Introduces the method of measuring wall bushing dielectric loss factor and judgment. Through the analysis of the reasons of casing collapse equipment, dielectric loss test of abnormal data of a $66 \mathrm{kV}$ substation C wall.

Wall bushing is an important equipment widely used in power system, it is the role of the high voltage wires safely through the ground walls, which is connected with other equipment. Therefore, it has the function of insulation, but also has a mechanical fixed effect.

Once the insulation is damaged, the operation of high voltage bushing may cause flashover and discharge, which may cause the breakdown of insulation, which will bring loss to the safe operation of power system. In the structure of the high voltage bushing, the absolute distance between the metal flange and the conductive rod is small, and the electric field intensity in the operation is large, and the insulation requirement is high, and the fault is easy to be out of order. ${ }^{[1]}$
\end{abstract}

\section{The Test Principle and Method of Wall Bushing Dielectric Loss}

\section{Principle of dielectric loss angle measurement.}

In the alternating electric field, the angle between the amount of current flowing through the dielectric and the voltage phasor $(\Phi)$ of the complement $(\delta)$, referred to as the dielectric loss angle.

Dielectric loss tangent tan $\delta$ also called the dielectric loss factor refers to the dielectric loss tangent of dielectric loss angle tangent, referred to as. The definition of dielectric loss factor is shown.

$$
\text { Dielectric loss factor }(\tan \delta)=\text { active power } \quad(\mathrm{P}) / \text { Reactive power }(\mathrm{Q}) \times 100 \%
$$

Phasor diagram can be obtained if the current phase and voltage phase are obtained. As shown. $u(t)=U_{1}\left[\sin \left(2 \pi f_{1} t\right)+m \sin \left(2 \pi f_{\mathrm{IH}} t+\theta_{\mathrm{IH}}\right)\right]$
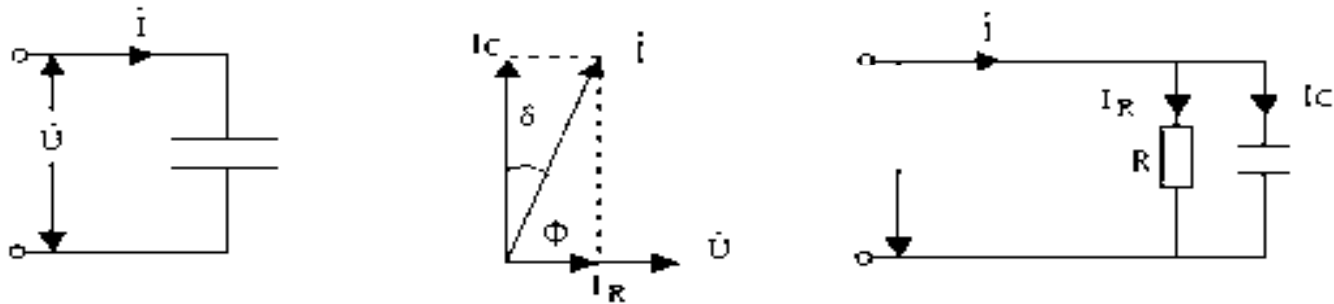

The total current can be decomposed into the capacitance current Ic and the resistance current IR synthesis as shown.

$(\operatorname{tg} 8)=\frac{P}{Q} \times 100 \%=\frac{U I_{R}}{U I_{c}} \times 100 \%=\frac{I_{R}}{I_{C}} \times 100 \%$

This is the loss angle $\delta=\left(90^{\circ}-\Phi\right)$ Tangent. So the digital instruments now in essence, is obtained by measuring the dielectric loss factor or phi $\delta$. Dielectric loss measurement is a traditional and 
effective method to judge the insulation condition of electrical equipment. The decrease of insulation capacity is directly reflected by the increase of dielectric loss. Further analysis of the reasons for the decline of insulation, such as: insulation moisture, insulation oil pollution, aging and so on.

Measurement of dielectric loss at the same time, also can get the amount of test products. If one or several of the multiple capacitive screens have a short circuit and open circuit, there is a significant change in the capacitance, so the capacitance is also an important parameter. ${ }^{\text {[2] }}$

The measurement method of dielectric loss of bushing.

In routine experiments, we aimed at the main characteristic of the wall bushing dielectric loss measurement and measuring the insulation resistance and capacitance value figure tangent.

The measurement of dielectric loss angle tangent value of bushing is more sensitive, in order to find the insulation condition of the wall bushing for more accurate definition. Can be more sensitive to reflect the insulation damp or other local defects. ${ }^{[3]}$

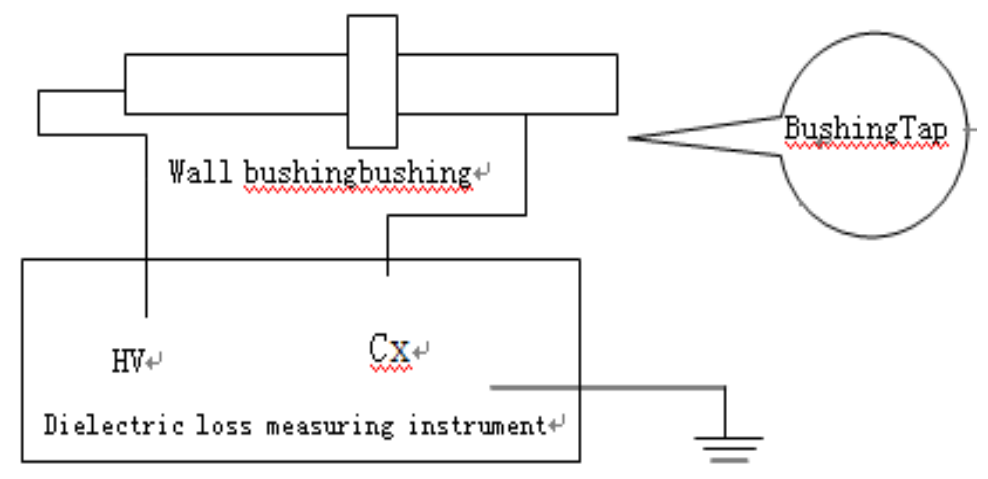

\section{Fault Analysis of Wall Bushing}

\section{Failure phenomena.}

In order to ensure the normal operation of equipment, testing personnel in March 5, 2014, the national network of Jinzhou power company for routine test on a 66 thousand volt substation 66 thousand volt wall bushing. The data in the test are shown in the following table:

\begin{tabular}{|c|c|c|c|c|}
\hline Phase & Brand capacitor & $\mathrm{Cx}(\mathrm{PF})$ & $\operatorname{tg} \delta \%$ & $\triangle \mathrm{C} \%$ \\
\hline $\mathrm{A}$ & 375 & 387.6 & 0.02 & 3.36 \\
\hline $\mathrm{B}$ & 380 & 382.6 & 0.38 & 2.02 \\
\hline $\mathrm{C}$ & 373 & 550.1 & 14.07 & 47.48 \\
\hline
\end{tabular}

Found C phase casing capacitance 550.1pf (Nameplate capacity 373pf, Excessive capacitance 47.48\%), Dielectric loss $14.07 \%$ (Should be less than $0.5 \%$ ).

The test staff then historical test data of the wall bushing for search, following the October 15, 2010 handover of the test data of bushing:

\begin{tabular}{|c|c|c|c|c|}
\hline Phase & Brand capacitor & Cx (PF) & $\operatorname{tg} \delta \%$ & $\triangle \mathrm{C} \%$ \\
\hline A & 375 & 385.3 & 0.04 & 2.75 \\
\hline B & 380 & 389.0 & 0.04 & 2.37 \\
\hline C & 373 & 384.0 & 0.03 & 2.95 \\
\hline
\end{tabular}

After comparing the history test data, according to the "state maintenance test procedures" seriously exceed the standard test results of power transmission equipment. Preliminary judgment possible bushing insulation damp or short circuit breakdown capacitance screen ${ }^{[4]}$ 
Table 1 High pressure casing inspection project

\begin{tabular}{|c|c|c|c|}
\hline Inspection items & Datum cycle & Requirement & $\begin{array}{l}\text { Description } \\
\text { clause }\end{array}$ \\
\hline Appearance check & \multirow{3}{*}{$\begin{array}{c}330 \mathrm{kV} \text { and above: } \\
2 \text { weeks } 220 \mathrm{kV}: 1 \\
\text { months } \\
110 \mathrm{kV} / 66 \mathrm{kV}: 3 \\
\text { months }\end{array}$} & no abnormalities & \multirow{3}{*}{ 5.6.1.1 } \\
\hline $\begin{array}{c}\text { Check the oil level and } \\
\text { leakage (Oil filled) }\end{array}$ & & no abnormalities & \\
\hline $\begin{array}{c}\text { Gas density value check } \\
\text { (Inflation) }\end{array}$ & & accordance with the requiement & \\
\hline
\end{tabular}

Table 2 High pressure casing routine test project

\begin{tabular}{|c|c|c|c|}
\hline Test item & Datum cycle & Requirement & $\begin{array}{c}\text { Description } \\
\text { clause }\end{array}$ \\
\hline thermography testing & $\begin{array}{c}\text { 330kV and above: } \\
1 \text { months } \\
220 \mathrm{kV}: 3 \text { months } \\
\text { 110kV/66kV: Half } \\
\text { a year } \\
\end{array}$ & no abnormalities & 5.6.1.2 \\
\hline insulation resistance & 3years & $\begin{array}{l}\text { a) main insulation : } \geq 10000 \mathrm{M} \Omega \\
\text { (Attention value) } \\
\text { b) Bushing Tap to the groung: } \\
\geq 1000 \mathrm{M} \Omega \text { (Attention value) }\end{array}$ & 5.6.1.3 \\
\hline $\begin{array}{c}\text { Capacitance and dielectric } \\
\text { loss factor }\left(20^{\circ} \mathrm{C}\right) \\
\text { ( Capacitor type })\end{array}$ & 3years & $\begin{array}{l}\text { 1. the initial value of the } \\
\text { capacitance difference is not more } \\
\text { than } \pm 5 \% \text { (Warning value) } \\
\text { 2. dielectric loss factor to meet } \\
\text { the requirements of the following } \\
\text { table: } \\
500 \mathrm{kV} \text { and above } \leq 0.006 \\
\text { (Attention value) } \\
\text { Others (Attention value) : } \\
\text { Oil-impregnated paper: } \leq 0.007 \\
\text { PTFEwinding insulation: } \\
\leq 0.005 \quad \text { Resin impregnated paper: } \\
\leq 0.007 \quad \text { adhesive paper } \\
\text { Resin } \leq 0.015\end{array}$ & 5.6.1.4 \\
\hline $\begin{array}{c}\mathrm{SF}_{6} \text { Gas humidity } \\
\text { detection (Inflation) }\end{array}$ & 3years & accordance with the requiement & 8.1 \\
\hline
\end{tabular}

Test and maintenance personnel will be immediately removed to check the casing without exception, remove the umbrella skirt and found traces of discharge occurs between the indoor terminals sixth, seventh fixed flange lateral direction skirt below sixth umbrella skirt found a hole. (as shown below)

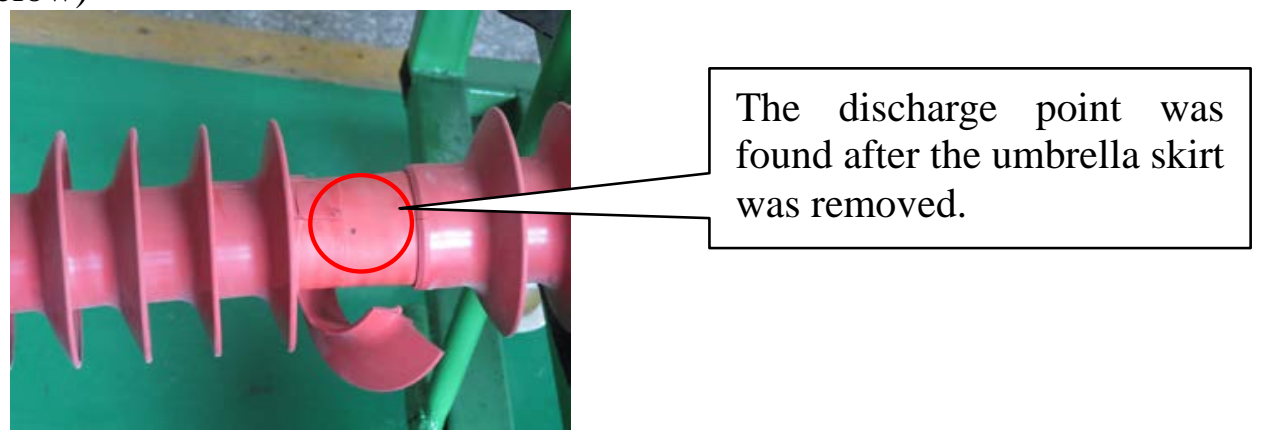

\section{Disintegrate.}

The casing through the return to factory inspection, remove the heat shrinkable insulation jacket was found, sixth and twelfth along the wall bushing along the outer winding capacitance screen are 
affected by the presence of force deformation, a first layer capacitance screen can be seen directly. (as shown below)

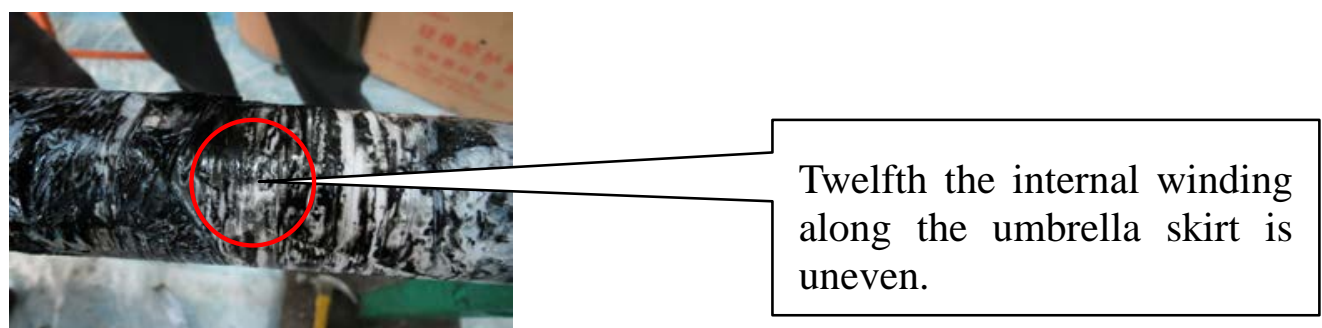

The disintegration of layers of dig inspection found sixth small holes along the wall bushing, Ninth edge from the outside to the inside of the three layer capacitive discharge, sixth, ninth and twelfth along the 90 degree angle from the outside to the inside of the two layer capacitive discharge. (as shown below)

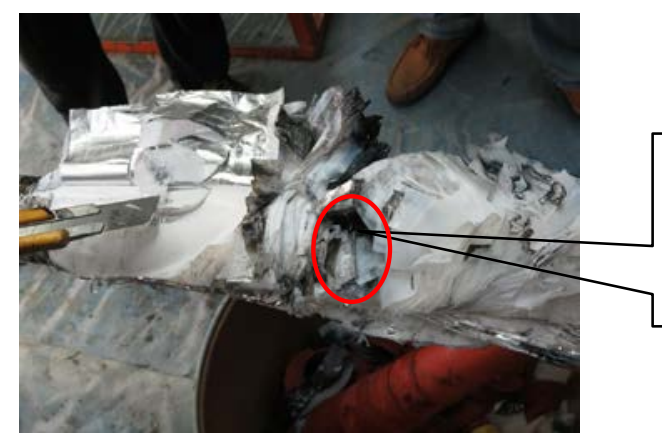

Sixth along the umbrella skirt from the outside of the three layer capacitor screen discharge

\section{Cause analysis.}

The outer insulation deformation phenomenon discovered by disintegration, preliminary analysis of the production process due to the outer insulation winding uneven, fastening degree insufficient, at the same time in the process of extrusion force by packing and transportation, resulting in deformation of outer insulation. The operation of the electric power in the casing vibration and the effect of thermal expansion and contraction, the uneven distribution of electric field strength of casing, easily lead to insulation breakdown, in the long time accumulation effect caused by outer insulation breakdown and discharge.

\section{Conclusion}

a. Through regular dielectric loss test of wall bushing, equipment defects can be found in a timely manner, has important significance for the safe operation of equipment.

b. Dielectric loss factor and capacitance can be effectively found insulation aging, moisture, cracking, pollution and other undesirable conditions.

c. This kind of casing should shorten the routine test cycle, and find the abnormal data to be replaced in time.

d. Infrared temperature measurement at the end of the screen. After the end of the casing is broken, the high voltage generated on the screen will produce suspended discharge, which can cause local overheating.

\section{Reference}

[1] Li Jinglu. Test and diagnosis of high voltage electrical equipment [M]. Beijing: China Water Conservancy and Hydropower Publishing House, 2008.

[2] Chen Huagang. Preventive test method and diagnosis technology of electric power equipment [M]. Beijing. China power press.2009

[3] Li Jianming, Zhu Kang. Preventive test method and diagnosis technology of electric power equipment [M]. Beijing: China power press, 2004. 
[4] State Grid companies.Q/GDW 168-2008 State maintenance testing procedures for power transmission equipment [S]. Beijing: China power press, 2008. 